\title{
Recent topics of candidate antigens for immunological control of ixodid ticks
}

\author{
Recent topics of candidate antigens for immunological control of ixodid ticks
}

Saiki Imamura, Satoru Konnai, Kazuhiko Ohashi \& Misao Onuma

\begin{abstract}
Ticks have been recognized as harmful parasite since ancient times. At present immunological protection of host against ticks is the most practical and sustainable tick control method, which is more suitable to natural environment compared to the current use of acaricides. Recently, focuses on the development of anti-tick vaccine are the identification, molecular cloning and in vitro production of recombinant protein, responsible for executing key roles in regulating physiology, modulation of host immune response and pathogen transmission via ticks. Among several works, serine protease inhibitors have been thought as one of the most interest vaccine candidates, because serine protease inhibitors are mainly involved in the maintenance of homeostasis. In the current review, we would like to introduce selected examples covering aspects of tick vaccine antigen identification and analyses, because advances in vector molecular biology open new possibilities for vaccine development. In dealing with this subject, contents were mainly divided into tick salivary gland associated molecules (exposed antigens) injected into the host during tick feeding and no salivary gland molecules (concealed antigens). While emerging the fact that serine protease inhibitors belong to either exposed or concealed antigens, the utility of serine protease inhibitors for the candidate vaccine have been discussed separately because of the importance of serine protease inhibitors in the physiology of several organisms including ticks. Advances in tick vaccine development and related subjects are regularly reviewed and in this paper, referred citations of excellence are suggested as additional reading.
\end{abstract}

Key words: tick, vaccine, immunization, serpin, Boophilus microplus, Haemaphysalis longicornis.

\section{RESUMO}

Os carrapatos têm sido reconhecidos como parasitos nocivos desde os remotos tempos. A proteção imunológica é o método de controle o mais prático e sustentável para controle do carrapato, pois é mais apropriada ao meio ambiente do que o uso de acaricidas. Atualmente, os focos no desenvolvimento de vacina contra carrapato são a identificação, a clonagem e a produção in vitro de proteínas recombinantes que apresentem funções importantes na fisiologia do carrapato, na modulação da resposta imune do hospedeiro e na transmissão de patógenos pelos carrapatos. Entre diversos alvos, os inibidores de serinoproteases são um dos mais interessantes candidatos, pois estão envolvidos manutenção da homeostasia do carrapato. Na presente revisão, serão apresentados alguns exemplos selecionados que enfocam aspectos da identificação e de análises de antígenos vacinais, pois os avanços na biologia molecular do vetor permitem novas possibilidades para o desenvolvimento de vacinas. Dentro deste tópico, o texto foi dividido, principalmente, nas moléculas associadas à glândula salivar (antígenos expostos que são inoculados no hospedeiro durante uma infestação natural) e, em moléculas não presentes na glândula salivar (antígenos ocultos). Mesmo, sendo os inibidores de serino-proteases antígenos expostos e/ou ocultos, o uso de inibidores de serino-proteases foi discutido separadamente por causa da sua importância na fisiologia de diferentes organismos, incluindo os carrapatos. Os avanços no desenvolvimento de vacinas contra carrapato e tópicos relacionados são regularmente alvos de revisões. Neste trabalho são referenciadas excelentes contribuições sugeridas como leitura adicional.

Descritores: carrapato, vacina, immunização, serpina, Boophilus microplus, Haemaphysalis longicornis. 


\section{INTRODUCTION}

\section{CONTROL METHODS}

\section{IMMUNOLOGY PROTECTION}

\section{Characteristics of exposed and concealed antigens}

2. Vaccine development using exposed antigens

3. Vaccine development using concealed antigens

\section{Serine protease inhibitors}

4.1 BPTI-kunitz family derived from ticks.

4.2 Serpin

4.3 Small molecular weight serine protease inhibitors

4.4 Anti-tick vaccine trial using serine protease inhibitors

\section{Future challenge - optimal tick vaccine}

5.1 Tick vaccine against multiple tick species

5.2 Dual action vaccine

\subsection{Transmission blocking vaccine}

\section{CONCLUSION}

\section{INTRODUCTION}

Ticks have been recognized as harmful parasite since ancient times. While ticks are also important as vectors of pests, they are mostly known for their roles as vectors, particularly of animals [69,74]. Ticks surpass all other arthropods in the number of and variety of pathogens which they can transmit to domestic animals, and are ranked 2nd next to mosquitoes as vectors of human diseases [56,69]. Ticks affect livestock production as described below either through their role as vectors of disease or by their feeding activities. For examples, losses due to direct tick feeding result in loss of weight, damaged hides, reduced milk production. In the estimation by Norval et al. [54], weight loss in cattle is estimated as 4.4 grams per Rhipicephalus appendiculatus female and 10 grams per Amblyomma haebraeum female. The annual global cost of controlling ticks and tick borne diseases, together with the reduced livestock productivity amounts to billion of dollars, though the precise figures for most countries are insufficient [16]. According to an estimate by Surtherst et al [71], ticks affect approximately 800 million cattle and a similar number of sheep world-wide, and monetary losses due to tick borne diseases alone on the cattle industry were estimated at approximately US\$ 7 billion [60]. The magnitude of the negative impact caused by ticks on livestock production leads to neces- sitate incorporation of several tick-control programs into modern livestock management practices.

Advances in tick vaccine development and related subjects are regularly reviewed and the reader is referred to excellent reviews by Tellam et al [74], Nuttall et al [55], Mulenga et al [44], De la Fuente and Kocan [11], Willadsen [92] and Willadsen and Jongejan [94], for further reading.

\section{CONTROL METHODS}

Currently, the mainstay of the tick control method heavily relies on the use of chemical acaricides. However, the use of acaricides is associated with a number of disadvantages such as chemical pollution of the food chain and environment as well as the rapid development of resistance against acaricides by ticks [52,74]. Especially, reducing effectiveness of acaricides is in certain instances, because rapid development of tick resistance to new compounds might discourage efforts to discover new acaricides in the aspect of the high cost for research, development and registration [89]. In addition, this method needs consistent application of acaricides, making the method labor intensive and very costly, especially during the rain season in tropical and subtropical climates. When the population of ticks becomes peak, acaricides have to be applied twice per week to maintain low tick populations [43]. 
Failure to continue the strict application of acaricide results in a rapid propagation of tick populations. For instance in Zimbabwe during the liberation struggle, tick control was suspended for 7 years, resulting in a flare up of the Rhipicephalus appendiculatus tick population and an increased number of theieriosis cases [53]. As taken these results into consideration, it is necessary to develop alternative methods for tick control.

The alternative tick control methods have also been considered so far and they could be divided into 3 groups, biological control of ticks by introducing the pathogens or predators into the tick habitats, habitat modifications by planting tick-killing or repelling vegetation, and immunological control of ticks [69]. Though some of these approaches were proved effective, most of these methods have not been continued, because they have not been practical in tick control programs as such apart from immunological controls of ticks $[34,57,88]$. Advantages of anti-tick vaccines/immunological tick control would include, specificity of target species, environmental safety, absence of human health risk, no residues in food products, ease of administration and cost [89]. Immunological protection against tick infestation depends on the fact that host can naturally develop resistance against tick feeding after repeated feeding. Acquired resistance to tick infestation is expressed as reduced engorgement weight, increased duration of feeding, impaired production and viability of ova, inhibition of moulting and death of feeding ticks $[87,89]$.

\section{IMMUNOLOGY PROTECTION}

As referred to Wikel [89], acquired resistance to tick infestation was reported for the first time by Johnston and Bancroft in 1918. They attributed the resistance against ticks in cattle to the substances introduced by ticks into the host during feeding and the resistant cattle developed cutaneous exudates at attachment sites. Experimental analysis of the basis for acquired resistance to tick feeding started with the work by Trager [75], who reported that guinea pigs developed systematic immunity after one infestation with $D e$ mancenteor variabilis larvae. Trager also proved that the performance of larval ticks of $D$. variavilis feeding on guinea pigs previously exposed to tick feeding was inferior compared to those feeding on naive guinea pigs. These observations have been confirmed by a series of studies as reviewed by Willadsen [90] and Opdebeeck [57]. There are several researches using crude tick homogenates as vaccine antigens, and have succeeded in inducing some levels of protective antitick immunity warranting further studies to develop vaccines against ticks. Though progress toward the development of anti-tick vaccine was obstructed for a long time by the lack of efficient methods to produce tick vaccine antigens in sufficient amounts for immunization, it has become from a possibility to a reality by the recent advance of molecular biological technology [64]. One practical example towards the development of anti-tick vaccine against 1-host tick has been demonstrated by an Australian group, which reported the successful development and commercialization of a recombinant anti-Boophilus microplus vaccine based upon the tick midgut-associated molecule, Bm 86 [66,74,91,93]. Though these studies provided important evidence on the reliability and practicability of the DNA biotechnology with respect to the production of recombinant tick-associated antigens, studies on other major 3-host tick species such as Haemaphysalis, Rhiphicephalus and Amblyomma are still far from being practical.

Recently focus on the development of antitick vaccine is the identification, molecular cloning and in vitro production of recombinant proteins, which could play key roles such as regulating physiology, modulation of host immune response and transmission of pathogens by ticks [44]. Therefore, the overall objective of the present study aimed at the identification, cloning and expression in vitro as well as assessing the protective efficacy of recombinant tick molecules which could be applicable for the field conditions.

\section{Characteristics of exposed and concealed antigens}

Traditionally, tick molecules are categorized into two groups [93]. The first is exposed antigens that are secreted in tick saliva and introduced into host's bite site during tick attachment and feeding. Therefore antigen derived from saliva is usually called as exposed antigens. As these molecules are exposed to the host by every tick feeding, acquired immunity against exposed antigens are naturally established and boosted by multiple feeding of ticks. Because once host acquired immunity against exposed antigens, host immune system reacts to those when a tick start secreting the molecules into bite site. Taken the fact into consideration, the levels of immunity induced by immunization with an exposed antigen would be sustained by every tick feeding. Especially, one such promising 
antigen is the cement protein, which is essential for assistance in the attachment to the host skin and is generally highly immunnogenic against host. In contrast, concealed antigens are not contact with host immune system by the natural feeding of ticks. Though concealed antigens do not induce immune responses by tick feeding, they are immunogenic when they inoculated artificially. Therefore it could be potential candidates for vaccine as long as the antigen encounters host immunoglobulines, entering the gut or hemolymph, and is associated with some physiological function for tick. However acquired immunity against concealed antigen dose not boosted by natural feeding of tick. For instance, the tick gut is representative concealed antigen.

Though exposed antigens have been identified by their ability to induce an antibody response through tick repeated infestations, existence of the bioactive molecules in tick saliva is potential problem for targeting exposed antigens. Namely tick saliva play important roles in creating optimal feeding environment and linked to the ability of pathogen transmission, these molecules are secreted into saliva to modulate host's hemostatic, inflammatory and immune system so that the tick can attach and feed successfully [8]. As a result, immunity induced by natural tick feeding or artificial immunization of exposed antigen reduces, and does not interfere with tick feeding even after repeated exposure to ticks [65]. Therefore it is thought to be difficult to induce sufficient levels of acquired immunity with exposed antigen, particularly if only a single exposed antigen is used to develop a vaccine. Moreover, intensive studies on random sequencing of tick cDNA library also supported this potential problem. Because gathering information from random sequencing analyses of cDNAs demonstrated that saliva component during feeding is mainly consisted of the bioactive molecules towards host defensive process like blood coagulation cascade, inflammatory, immune responses [48]. Theses bioactive molecules would interfere with the initiation of host immune response. On the other hand, vaccine targeting concealed antigen could not be interfered by the bioactive molecules $[55,93]$. However, repeated immunizations are required for maintaining the adequate levels of immunity. Basically, host immunoglobulines likely to interact with not only gut-derived antigens but also organs/tissues, because it is well known that host immunoglobulines pass though the midgut into hemocoel $[20,83]$. As a result of immunoglobulin passage into the body cavity, rapture/interference of the target molecules would occur.

\section{Vaccine development using exposed antigens}

Several exposed antigens have been expressed as recombinant proteins so far, and evaluated its efficacy for anti-tick vaccine (Table 1). The way to explore the exposed antigens is proceeding at the molecular level. Among various kinds of molecular biological techniques, immunoscreening analysis, using

Table 1. Representative exposed antigens evaluated as recombinat anti-tick vaccines.

\begin{tabular}{|c|c|c|c|c|}
\hline Antigen & Tick Species & Characterization & Property & Ref. \\
\hline $64 \mathrm{P}$ & R. appendiculatus & Cement protein & $\begin{array}{l}\text { Cross-reacting with concealed } \\
\text { antigens and different tick species }\end{array}$ & [76] \\
\hline p29 & H. longicornis & Cement protein & Effective against all tick stages & [45] \\
\hline HL34 & H. longicornis & Cement protein & $\begin{array}{l}\text { Effective against nymphal and } \\
\text { adult ticks }\end{array}$ & [77] \\
\hline RIM36 & R. appendiculatus & Cement protein & Not protective against cattle & {$[6]$} \\
\hline $\mathrm{RH} 50$ & R. haemaphysaloides & Cement protein & Effective against adult ticks & [97] \\
\hline Calreticulin & $\begin{array}{l}\text { A. americanum } \\
\text { D. variabilis Calreticulin } \\
\text { B. microplus }\end{array}$ & Calreticulin & Low immunogenicity in cattle & $\begin{array}{l}{[31]} \\
{[15]}\end{array}$ \\
\hline Immunoglobulin-binding proteins & R.appendiculatus & Immunomodulator & $\begin{array}{l}\text { Effective against feeding } \\
\text { performance slightly in guinea } \\
\text { pig model }\end{array}$ & [84] \\
\hline Histamine-binding protein & R. appendiculatus & Histamine-binding & $\begin{array}{l}\text { Adverse reaction in guinea } \\
\text { pig model }\end{array}$ & [58] \\
\hline
\end{tabular}


host sera from the host repeatedly fed by ticks, has been mainstay to explore exposed antigen. Because this method is theoretically supported by the fact that the antigen that could be screened is really exposed into host during feeding and immunogenic. While some of them are established as the effective antigen, no recombinant antigen has been developed commercially.

Immunoscreening of a partially fed adult female cDNA library of $H$. longicornis, using antiserum from a rabbit repeatedly fed with the tick, identified the p29 and HL34 of putative cement protein $[45,77]$. Immunization of rabbits with recombinant p29 lead to $40 \%$ and $56 \%$ mortality in larval and nymphal ticks, respectively, and a $17 \%$ reduction in engorgement weight of adult ticks. Efficacy of tick cement as vaccine antigens have been supported by several works [76,97]. On the other hand, RIM36, an immunodominant cement cone protein of $R$. appendiculatus induced a strong antibody response in tick-exposed cattle, but no protective immune response was induced by RIM36 [6]. Immunodominancy might be distinguished from protective immune response in principle. Among several exposed antigens, 64P showed unique characteristics, and was identified by random screening of cDNA library derived from pooled male and female salivary glands of ticks [76]. Though 64P is originally cloned as exposed antigen, it could be reactive with internal tissues, suggested that 64P possess more than one conserved antigenic epitope. Moreover challenge experiment using guinea pig model, recombinant 64P immunization is cross protective against different tick stages and species, causing mortality of up to $80 \%$. Except for the cement molecules described above, histamine-binding protein [58], immunoglobline-binding protein [86] and calreticulin [15,31] from salivary gland were evaluated for the candidate vaccine. For examples, calreticulin, which is a calcium binding protein normally found in endoplasmic reticulum, was secreted in tick saliva, and was firstly identified in a cDNA library of partially fed female Amblyomma americanum salivary glands. In a rabbit model, immunization with recombinant $A$. americanum calreticulin caused necrotic cutaneous lesions on tick challenge. Though sera collected from the dog fed by $R$. appendiculatus recognized recombinant $B$. microplus calreticulin, the recombinat did not induce an antibody response in cattle. This phenomenon might be caused by the genetic conservation of carleticulin between the host and tick.

While vaccine development using exposed antigens would have some difficulties as described before, the cement proteins are possible candidates for the further assessment in cattle trials.

\section{Vaccine development using concealed antigens}

As hidden from the host immune system, the vaccine candidate molecules derived from tick internal tissues/organs are so called as concealed antigen (Table 2). Originally, the concept of using concealed antigens to immunize the hosts against ticks was based

\begin{tabular}{|c|c|c|c|c|}
\hline Antigen & Tick Species & Characterization & Property & Ref. \\
\hline Bm86 & B. microplus & Gut protein; unknown function & Commercial vaccine & [92] \\
\hline Bm95 & B. microplus & Gut protein; unknown function & Bm86 sequence variant & [22] \\
\hline Bm91 & B. microplus & Carboxy dipeptidase & Increased efficac & {$[66]$} \\
\hline BMA7 & B. microplus & Mucin-like membrane & Increased efficac & [42] \\
\hline $\mathrm{P} 27 / 30$ & H. longicornis & Troponin I-like protein & Impairs tick feeding in mice model & {$[96]$} \\
\hline Serpins & H. longicornis & Serine protease inhibitors & $\begin{array}{l}\text { Effective against nymphal and } \\
\text { adult ticks in rabbit model }\end{array}$ & {$[70,25]$} \\
\hline Subolesin (4D8) & I. scapularis & Unknown function & $\begin{array}{l}\text { Effective against adult ticks } \\
\text { in sheep model }\end{array}$ & [3] \\
\hline \multirow[t]{2}{*}{ Voraxine } & A. hebraeum & Male engorgement factor & $\begin{array}{l}\text { Effective against female } \\
\text { engorgement and reproduction } \\
\text { in rabbit model }\end{array}$ & {$[86]$} \\
\hline & & Reservoir of heme & $\begin{array}{l}\text { Effective as naive protein but not } \\
\text { the recombinant form }\end{array}$ & [73] \\
\hline
\end{tabular}


on the idea of inducing antibody targeting tick molecules that play essential functions. Therefore, in order to explore the effective antigen, molecular identification, characterization, cloning and generation of recombinant protein is necessary to evaluate the vaccine efficacy. The mechanism why antibody against internal molecules in ticks would be effective is explained as follows. Because it is well known the fact that antibody could pass intact through the midgut into hemolymph [36], and then might be move to the each internal organ. Therefore the antibodies would induce a disruption of the essential functions and kill the feeding ticks and the engorged ticks. Work on the development of recombinant vaccines against cattle tick $B$. microplus represents one of the most significant advances to date in the use of concealed antigens to immunize cattle against ticks. Three concealed antigen, Bm86 [94], Bm91 [66] and BMA7 [42] have been identified from gut wall of the cattle tick Boophilus micloplus. Especially, vaccine based on $\mathrm{Bm} 86$ became the first ever anti-arthropod vaccine commercially available [74]. Bm91 and BMA7 were later identified to enhance the efficacy of the BM86-based vaccine. The antitick effect induced by either Bm91 or BMA7 alone was strikingly less effective, when compared to that induced by recombinant Bm86 alone. However when either of the two antigens (BM91 or BMA7) was used in a cocktail with Bm86, anti-tick immunity induced by the cocktail was much more efficient than that observed with the commercial vaccine [42,95]. Tick gut wall antigens interact with specific immunoglobulins taken up in the blood meal from the immunized host, and then antibody binding potentially causes lysis of the gut wall, interfering with digestion of the blood and subsequent egg production $[1,20]$. The strong antibody responses are injurious to adult tick survival, though it is short lived [92]. Because the Bm86 antigen is normally hidden from host immune system, natural infestation does not boost an immune response. Vaccination may be required at 6-month interval to sustain the immunity [13]. One of the most significant observations from the work on a vaccine against tick gut is the fact that Bm86 provides the proof of concept for anti-tick vaccines. However anti-tick vaccines for other major tick species are not still being practical. Except for gut-derived molecule, several antigens from various tissues have been expressed as recombinant and evaluated as vaccine candidates.
A recombinant prepared from a P27/30 troponin I like protein of $H$. longicornis, is abundantly expressed in muscle, induce a protective immunity in mice model. It demonstrated the prolonged pre-feeding period of adult ticks and reduced attachment rate of larval ticks [96].

Immunization of sheep with 4D8, a $21-\mathrm{kDa}$ putative soluble cytoplasmic protein of Ixodes scapularis, reduced infestation levels, prolonged engorgement and resulted in smaller egg masses of adult $I$. scapularis. Subolesin (4D8) was recently discovered in I. scapularis by expression library immunization (ELI) in combination with sequence analysis of expressed sequence tags (ESTs) in a mouse model of larval infestations. Subolesin, a highly conserved protein involved in modulation of tick feeding and reproduction, was protective against all tick developmental stages when used in cDNA and/or recombinant protein immunization experiments [3]. Analysis of subolesin DNA and protein sequences in 11 ixodid tick species has demonstrated identity/similarity between $65 \%-97 \%$ and $60 \%$ $98 \%$, respectively. Furthermore, homologues of tick subolesin were identified in other organisms ranging from nematodes to humans. Taken these facts into consideration, subolesin might be a candidate conserved tick-protective antigen that could be used in vaccine formulations for the control of multiple tick species. Preliminary experiments using the recombinant $I$. scapularis subolesin have shown a protective effect against Dermacentor variabilis and A. americanum. These results provide preliminary data on the feasibility of controlling infestations by multiple tick species using conserved protective antigens [11]. Together with the 64P, 4D8 is the suitable candidate for the universal vaccine.

Voraxine is a male specific protein from the gonads of A. hebraeum, induced during feeding [86]. At the result of immunization of rabbits with voraxine, normal engorgement of mated female A. hebraeum was impaired. Basically, it could be expected that targeting gonad-associated protein would have some possibility to affect the reproduction of ticks. This could be a new concept with great impact, because interference of the reproduction directly leads to the reduction of second generation.

\section{Serine protease inhibitors}

While emerging the fact that serine protease inhibitors belong to either exposed or concealed anti- 
gens, I have discussed the utility of serine protease inhibitors, separately from the chapters introduced above. First of all, general information of serine protease inhibitors is provided in this chapter.

In vertebrates, serine proteases have been well studied to play an important role in regulation of several physiological functions such as blood coagulation, fibrinolysis, complement activation and tissue modeling $[32,62,67]$. In invertebrates, these proteases are involved in fundamental physiological roles like the limulus hemolymph clotting cascade [29,30], innate immune response [28], molting and prophenoloxidase cascade $[32,33]$. All serine proteases are usually regulated by endogenous protease inhibitors with the target canonical binding loop, which interact with the target enzyme active loop [7]. Based on the primary and threedemensional structures of the protease inhibitors, they are classified into at least 18 families [38]. Among them, the following six families: Kazal, BPTI-Kunitz, ?Macroglobulin, Serpin, Pacifastin and Bombyx have been identified from hemolymph and saliva in invertebrates $[32,61,68]$. Especially in hematophagous arthropods, serine protease inhibitors, which belong to BPTIKunitz, are mainly active toward thrombin and factor $\mathrm{Xa}$, the two key enzymes of blood coagulation cascades [10].

As mentioned previously, one approach to evaluate exposed/concealed antigens as vaccine candidates is to target molecules involved/contributed in key physiological functions. Therefore, serine protease inhibitors are theoretically thought to have potential as antigen targeting tick homeostasis, and intensive efforts had been done to explore serine protease inhi- bitors for application of vaccine trial. Among tick species, serine protease inhibitors belong to BPTI-Kunitz, Serpin and small molecules (not categorized yet) have been discovered so far. Representative serine protease inhibitors, which have previously been cloned, were introduced in this chapter.

\subsection{BPTI-kunitz family derived from ticks}

Ticks are rich source of serine protease inhibitors, which belong to the BPTI-kunitz type family. The BPTI-kunitz fold (basic trypsine inhibitor fold) is characteristics of a family of serine protease inhibitors. These inhibitors are polypeptides $(<65$ residues) with 6 cysteines arranged in a characteristics disulfide bond [39]. The basic structure consists of an Nterminal 310-helix around the first cystein, a central double stranded anti-parallel ?-sheet linked by a hairpin loop and a C-terminal three turn a-helix. Several proteins with the BPTI-kunitz fold have been identified in tick saliva, and speculated as inhibitor of host coagulation cascade during their feeding (Table 3). Tick anti-coagulant peptide (TAP) and fXaI, as well as ornithodorin and savignin (Thrombin inhibitors) have been well studied for the soft ticks, M. moubata and Ornithodoros savignyi, respectively $[23,51,81,85]$. As ixodid ticks are responsible for the transmission of tick borne diseases, many studies have also been performed using different stages of these species. BmTI have been identified from larva of the hard tick $B$. microplus that inhibit trypsin, elastase and kallikrein [72]. Ixolaris have been reported as the fVII/tissue factor complex inhibitor with double-domain BPTI-like protein [19]. The random sequence analysis of expression tagged cDNA library revealed that the proteins be-

\begin{tabular}{|c|c|c|c|c|c|}
\hline Name & Species & Target & Mr (kDa) & Vaccine experiment & Ref. \\
\hline \multicolumn{6}{|l|}{ Soft ticks } \\
\hline TAP & O. moubata & $\mathrm{fXa}$ & 7 & - & [85] \\
\hline ornithodrin & O. moubata & Thrombin & 12 & - & [81] \\
\hline fXal & O. savignyi & $\mathrm{fXa}$ & 7 & - & [23] \\
\hline savignin & O. savignyi & Thrombin & 12 & - & [51] \\
\hline \multicolumn{6}{|l|}{ Hard ticks } \\
\hline $\mathrm{BmTl}$ & B. microplus & Kallikrein & 18 & $\begin{array}{l}\text { Effective against larval } \\
\text { ticks in cattle model }\end{array}$ & {$[4,72]$} \\
\hline Ixoraris & I. scapularis & FVIIa-TF & 16 & - & [19] \\
\hline
\end{tabular}


long to this family is mainly contained in tick saliva, and targeted toward host blood coagulation factor.

\subsection{Serpin}

Approximately 500 serpins have been identified in a large variety of species so far. In human plasma, they make up approximately $2 \%$ of the total protein amount, of which $70 \%$ is $\alpha-1$-antitrypsine. Both extracellular and intracellular serpins are identified [82]. Members of the superfamily of serine protease inhibitors are expressed in a cell-specific manner and are involved in a number of fundamental biological process such as blood coagulation, complement activation, fibrinolysis, angiogenesis, inflammation and tumor suppression $[10,67]$. On average, serpins are 350400 amino acids long. The protein structure of serpins is usually characterized by $3 \beta$-sheets, and 8 or $9 \alpha$ helices. Typically, the future of serpins is the reactive center loop (RCL), which is the motif composed of approximately 20 amino acids, located near the Cterminal end of the protein. The RCL contains a scissile bond between amino acid residues called P1 and P1', which is cleaved by the target protease. Once cleaved, the RCL domain traps the target protease and moves to the opposite pole of the serpin through the $\beta$-sheet $\mathrm{A}$. This association results in an irreversible loss of structure and distortion of both protease and the serpin. The hinge region inside the RCL (amino acids P15-P9) is implicated in the stabilization of the interaction with the protease and provides mobility for the integration of the RCL in $\beta$-sheet A. Some serpin family members, while structurally similar to serpins, have no inhibitory activities. These non-inhibitory serpins include ovalbumin, gene $\mathrm{Y}$ protein, hormone binding protein, corticosteroid binding globulin and thyroxine binding globulin. The serpins described above are included either because extensive studies have been failed to show inhibitory properties or they have been only poorly characterized to date, with no demonstration of protease inhibition. And the RCL sequences are either unusual for inhibitory serpins or thought to contain residues inimical to the efficient operation of the loop insertion mechanism.

A few serpins have been recently cloned from the hard ticks B. microplus, H. longicornis, A. hebraeum, A. variegatum, $R$. appendiculatus and I. scapularis [27,35,46,70] (Table 5). Iris "Ixodes ricinus immunosupressor" was found in the tick saliva, and related to the pig leukocyte elastase inhibitor. Iris was demons- trated to interfere with the coagulation pathways and the fibrinolysis process via the RCL domain and with platelet adhesion via another functional domain [40]. HLS1 "Haemaphysalis longicornis serpin 1" and HLS2 "Haemaphysalis longicornis serpin 2" were found in the cDNAs constructed from tick midgut and hemolymph, and related to the anti-thrombin III and the Limulus intracellular coagulation inhibitor, respectively [27,70]. Naïve HLS1 was not secreted into host during the feeding, and mRNA transcripts were only detected from the midgut. These results indicated that naïve HLS1 is not involved in the host defensive process stimulated by tick feeding, but involved in the physiological functions of ticks. On the other hands recombinant HLS2 affected on activated partial thromboplastin time (APTT), which is a screening assay for deficiency of coagulation factors associated with intrinsic pathway. However naïve HLS2 was not secreted into host. The location where HLS2 expressed was hemolymph, suggesting that naïve HLS2 is involved in the maintenance of hemolymph circulation. Since the ticks are likely to have a coagulation cascade like Limlus. Rhipicephalus appendiculatus serpin-1, 2, 3 and 4 "RAS-1, $-2,-3$ and -4 " were also cloned from feeding tick [46]. Based on the sequence similarity of RAS-1, $-2,-3$ and -4 with other known serpins, they are also thought to be associated with physiological function of ticks. However functional assay using recombinant protein has never been done yet.

As considering the results introducing above, tick serpins are mainly existed in tick internal organs, and hidden from host except the report on Iris.

\subsection{Small molecular weight serine protease inhibitors}

Recently, Small molecules, which demonstrated an inhibitory activity of serine protease, have been cloned from hard tick Haemaphysalis longicornis (Table 4). The proteins, named madanin 1 and 2, were 7-kDa proteins and showed no significant similarities to any proteins previously identified [30]. Assays using human plasma demonstrated that madanin 1 and 2 prolonged dose-dependently both activated partial thromboplastin time and prothrombin time, indicating that madanin 1 and 2 could inhibit the common pathway of both intrinsic and extrinsic. Direct binding assay demonstrated that madanin 1 and 2 specifically interacted with thrombin. Furthermore, it was clearly shown that madanin 1 and 2 inhibited conversion of fibrinogen into fibrin by thrombin, thrombin-catalyzed 
Table 4. Serine protease inhibitor, which shows no significant similarities to any previously identified proteins.

\begin{tabular}{llcccc}
\hline \multicolumn{1}{c}{ Name } & Species & Target & Mr $(\mathbf{k D a})$ & Vaccine experiment & Ref. \\
\hline Madanin 1 & H. longicornis & Thrombin & 7 & - & {$[29,30]$} \\
Madanin 2 & H. longicornis & Thrombin & 7 & - & {$[29,30]$} \\
Chimadanin & H. longicornis & Thrombin & 7.6 & Low immunogenic & Unpublished data \\
\hline
\end{tabular}

Table 5. Representative molecules derived from ticks, which belongs to Serpin family.

\begin{tabular}{|c|c|c|c|}
\hline Acc. No./Name & Species & Vaccine experiment & Ref. \\
\hline CAC22469 & I. scapularis & - & - \\
\hline CAB55818 & I. scapularis & - & - \\
\hline AY312432 & B. microplus & - & - \\
\hline HLS1 & H. longicornis & $\begin{array}{l}\text { Incereased mortality rate during and after feeding of nymphal and } \\
\text { adult ticks in rabbit model }\end{array}$ & [70] \\
\hline HLS2 & H. longicornis & $\begin{array}{l}\text { Incereased mortality rate during and after feeding of nymphal and } \\
\text { adult ticks in rabbit model }\end{array}$ & [27] \\
\hline RAS-1 & R. appendiculatus & \multirow{2}{*}{$\begin{array}{l}\text { Immunization of cattle with a combination of RAS-1 and RAS-2 } \\
\text { induced a protective imunity against adult ticks }\end{array}$} & {$[26,46]$} \\
\hline RAS-2 & R. appendiculatus & & {$[26,46]$} \\
\hline RAS-3 & R. appendiculatus & \multirow{2}{*}{$\begin{array}{l}\text { Cocktail vaccine combined with RAS- } 3 \text {, RAS- } 4 \text { and RIM } 36 \text { induced } \\
\text { a protective immune response and partial interference of } T \text {. parva } \\
\text { transmission via tick in cattle model }\end{array}$} & {$[46]$} \\
\hline RAS-4 & R. appendiculatus & & {$[46]$} \\
\hline
\end{tabular}

activation of factor V and factor VIII, and thrombininduced aggregation of platelets without affecting thrombin amidolytic activity. These results suggest that madanin 1 and 2 bind to the anion-binding exosite 1 on the thrombin molecule, but not to the active cleft, and interfere with the association of fibrinogen, factor $\mathrm{V}$, factor VIII and thrombin receptor on platelets with an anion-binding exosite 1 . They appear to be exosite 1-directed competitive inhibitors. Following the report about madanin, novel thrombin inhibitor, named chimadanin, was also identified from the same tick [47]. In spite that chimadanin also showed no sequence similarity with other anticoagulants, anti-coagulant property and thrombin inhibitory activity were also observed by recombinant chimadanin.

Based on the fact that strategy toward anticoagulation of host blood is necessitate to continuous feeding of tick, anti-coagulant molecules in saliva seems to be highly evolved beyond our knowledge. Because information assembled from random sequence analysis of cDNA library constructed from the salivary glands during feeding included large number of the sequences that have no significant homology to other known molecules. It is natural to speculate that these unknown molecules supposed to be involved in the interference of host defensive process, since ticks highly adapt to a blood-feeding environment [41].

\subsection{Anti-tick vaccine trial using serine protease inhibitors}

A large number of vaccine candidates have been expressed as recombinant proteins and tested their suitability as vaccine candidates. In spite that serine protease inhibitors have been expected as vaccine antigen, the case reports evaluating serine protease inhibitors for vaccine candidates have been a few. However the vaccine effects of serine protease inhibitors against ticks have been actually observed in various experimental models (Table 2, 4 and 5). Andreotti et al [4] reported the immunization of host with a serine protease inhibitor (BmTI), which belongs to BPTIKunitz family, extracted from B. microplus larval ticks. As judged from the small molecular weight of BmTI, it is likely to be the component of tick saliva and could be secreted into the host bite site during feeding. Bos 
indicus Nelore breed calves, previously sensitized with BmTIs and challenged with tick larvae (20,000 larvae/ animal), showed $72.8 \%$ efficacy to interfere in tick development with $69.7 \%$ and $71.3 \%$ reduction of both tick number and egg weight, respectively. Sugino et al [70] and Imamura et al [27] reported the immunization of rabbits with serine protease inhibitor (HLS1, HLS2), respectively. HLS1 and HLS2 belong to Serpin family, and were induced during blood feeding of $H$. longicornis. Since the physiological role of HLS1 and HLS2 were postulated as a regulation of blood meal digestion and maintenance of hemolymph circulation, respectively, they have potential as an antigenic cocktail targeting tick homeostasis. In rabbit model, vaccination with recombinant HLS1 and HLS2 actually resulted in increased mortality of both nymphal and adult ticks. In our other experiment [26], cocktail vaccine trial using a combination of internal serpins (RAS-1and RAS-2) also demonstrated increasing mortality of nymphal ticks in cattle model. This could be a practical example for the utility of serpins as vaccine antigen for field application.

The concept of using serpins to immunize hosts against ticks was originally based on the idea on inducing antibody against the tick molecules that performed essential functions. In principle, uptake of the antibodies via a blood meal would then disrupt the essential functions and kill the feeding ticks and engorged ticks. Just as described above, antibody against tick serine protease inhibitor also seems to reach the place where naïve proteins are, and could compromise the function of naive protein. As a result of interference of naïve serine protease inhibitor, unbalance of tick homeostasis would occur and result in prolonged feeding and increased mortality. Based on the results introduced above, serine protease inhibitor could be an important molecule to advance in anti-tick vaccine development.

\section{Future challenge - optimal tick vaccine}

Though recombinant vaccines derived from cement, gut and serine protease inhibitor were assessed for their vaccine efficacy and demonstrated successful immunization on several kind of experimental animals, further exploring and characterization of candidates should be done for development of ideal vaccine. Application of the molecular biological techniques and genome informatics tool has great impact for the research on ixodid ticks with valuable results for tick vaccine development. Because it is clear that the advances for optimal vaccines against ticks requires well understanding of basic tick physiology. Constraction of expressed sequenced tag databases has been reported for B. microplus [9], A. americanum [25], A variegatum [50] and $R$. appendiculatus [49]. The transcriptome of tick salivary glands has been characterised in I. scapularis [79], I. ricinus [78], I. pacificus [18], A. americanum, D. andersoni [5] and H. longicorni [48]. The gathering sequence informations in tick species have to be used for functional analysis in order to annotate and select vaccine candidate. To achive this object, RNAi has been applicable for rapid analysis of systematic function. Because RNAi has been one of the most promising technologies for manipulating gene expression of target molecules where other genetic tools are not available. Therefore RNAi contributes to the rapid selection for the candidates based on the function of the target protein. On the other hand, even if systematic function of the molecules was not known or revealed, it could be potential candidate as long as it demonstrate the vaccine efficacy. Namely, to define the funciton of candidate is important but not essential, because the most considerable thing in the aspect of vaccine development is whether the antigen of interset could induce protective imunity or not. Expression library immunization (ELI) has a potential to explore the canditdate antigen efficiently, because the basis of ELI is dependent on the immunogenicity and induction of protective immunity. If it were combined with sequence anlysis of ESTs, ELI would support to find out both the promising candidate antigen and its putative function coincidently. The application of these technology to explore potential candidates could impact on tick vaccine development through the identification and characterization of tick-protective antigens.

Recent years, here emerged critical examples that have an insight into the advance of ideal conditions of anti-tick vaccine. The novel concept listed in this chapter would not be ignored for the development of anti-tick vaccine.

\subsection{Tick vaccine against multiple tick species}

A broad-spectrum/universal vaccine is one that targets not only all stages of ticks but also multiple tick species and ideally, all species. Highly conserved antigens between tick species potentially possess the properties for cross-resistance across all tick species and stages. Early experiments using $B$. microplus Bm86 demonstrated cross-protection against $B$. annu- 
latus and B. decoloratus infestations, and partial protection against Hyalomma and Rhipicephalus spp [12,14, 17]. However the protection against Ammblyomma spp [14] and some geographical strains of B. microplus [21, 22] was failed by the immunization of Bm86. These results supported the application of the Bm86 vaccines were widely available in regions where Boophilus spp. co-localized with other tick genera, as such frequently occurs in regions of America, Africa and Asia. Consideration of cross-resistance among different tick genera is important for the broadest application of vaccine. Trimnell et al [76] provided an example for the broad-spectrum vaccine using the putative tick cement protein as target molecule. Because ixodid tick species use cement to attach onto the host skin for feeding, cement is potentially conserved among multiple tick species. Based on this concept, they identified the $R$. appendiculatus 64P antigen, which demonstrated immune reactivity with $R$. sanguineus, I. ricinus, $A$ variegatum and B. microplus. 64P induced protective immunity against $R$. sanguineus and $I$. ricinus in guinea pig model, which may be useful for controlling tick species with broad-spectrum. Subolesin (4D8) was also discovered in I. scapularis by expression library immunization (ELI) in combination with sequence analysis of expressed sequence tag (ESTs) in a mouse model of larval infestation [2]. Subolesin was a protein with high sequence similarity among ixodid tick species, and expected to be involved in a modulation of tick feeding and reproduction. Immunization of sheep with recombinant Subolesin induced protective immunity against adult $I$. scapularis [3]. These supported a possibility of using Subolesin for controlling multiple tick species. As described previously, tick serpins were also characterized as an effective antigen with high conservation between ixodid tick species [27,46,70]. For example, HLS2 was discovered from partially fed $H$. longicornis by RACE method. Analysis of the HLS2 suggested that the HLS2 likely to be involved in maintenance of hemolymph circulation during feeding of ticks. Immunization of recombinant HLS2 with rabbit demonstrated increased mortality rate of both nymphal and adult ticks. Since homologous molecules with HLS2 were identified from $R$. appendiculatus, B. microplus, HLS2 may be a candidate for a tickprotective antigen that could be used in vaccine formulations for the control of multiple tick species. To develop the universal vaccine against tick species, it is important to identify and characterize tick molecules that are involved in a crucial function of tick, and are commonly existed among broad range of tick species.

\subsection{Dual action vaccine}

One of the most different properties between exposed and concealed antigen is whether repeated immunization is required to maintain elevated anti-body titers. Antibody titers induced by exposed antigens is boosted naturally through the tick infestation, because the target antigen is exposed to the host immune system during tick infestation. On the other hand concealed antigens are hidden from host immune system, therefore antibody titers are only maintained by repeated immunization of the antigen. However the advantages of using concealed antigens results from the unlikely possibility that ticks would have evolved a mechanism to effectively counteract the effect of the host immune system as had occurred with exposed antigens [93]. A recent study proposed new concept of the vaccine that combine the advantages of both exposed and concealed antigens. 64P, a $15 \mathrm{kDa}$ protein from $R$. appendiculatus, was identified as a putative cement protein involved in attachment and feeding of tick. Vaccination of guinea pigs with recombinant versions of $64 \mathrm{P}$ protein resulted in $48 \%$ and $70 \%$ reduction of the nymphal and adult infestation rates, respectively. Interestingly, the immune response induced by this exposed salivary antigen cross-reacted with concealed tick gut antigens [76].

\subsection{Transmission blocking vaccine}

An important aspect of controlling tick infestations is a reduction of the transmission of tick-borne pathogens. Therefore anti-tick vaccines should reduce the incidence of tick-borne diseases through reducing vector numbers in principle. The phenomenon of reduced transmission capacity of ticks fed on immunized animal has been observed with several works. Early experiments with Bm86 vaccines resulted in a reduction in the incidence of babesiosis together with a reduced number of tick infestation $[13,80]$. In recent work reported by Labuda et al [37], the transmission of tick borne encephalitis virus (TBEV) was prevented by the vaccination of the putative tick cement 64P in mice model, suggesting that $64 \mathrm{P}$ could be a potential candidate for transmission-blocking vaccines.

In our current study (Imamura et al unpublished data), immunization of cattle with a combination of recombinant serpin from $R$. appendiculatus induced a partial blocking of T. parva transmission via tick, 
quantified by Real-time PCR analysis. Though there was no direct association between tick serpin and pathogen, compromising the tick physiology induced by the immunization with serpin seemed to affect not only on a tick feeding activity but also on a vector capacity of ticks. Though these works mentioned above have some efficacy against vector capacity of ticks, innovative approach is needed to advance the transmissionblocking vaccines. Because vaccines designed for targeting anti-vector are required to distinguish antigens that induce protective immunity against ticks while preventing pathogen transmission.

There are only a few molecules, which have been proved as direct association between tick vector and the pathogen. Recent study by Pal et al [59] reported the identification of a tick receptor (TROSPA) that was required for B. burgdorferi colonization of I. scapularis. They demonstrated bacterial OspA was a ligand for TROSPA and the blocking of TROSPA by TROSPA antisera or by the repression of TROSPA expression with RNA interference (RNAi) reduced adherence to the I. scapularis gut in vivo. Following the discovery of TROSPA, Gomes-Solecki et al [24] demonstrated the reduction of Borrelia burgdorferi infection of $I$. scaplaris fed on mice immunized with an oral vaccine based in bacterial OspA, postulated by preventing bacterial adhesion to the tick receptor.

Ramamoorthi et al [63] reported that Salp15, an Ixodes scapularis salivary protein, inhibited $\mathrm{CD} 4^{+}$ $\mathrm{T}$ cell activation. Salp15 also inhibited the development of $\mathrm{CD}^{+}{ }^{+} \mathrm{T}$ cell-mediated immune responses in vivo, demonstrating the functional importance of this protein. Salp15 provides a molecular basis for understanding the immunosuppressive activity of $I$. scapularis saliva and vector-host interactions. Interestingly, the level of Salp15 expression was selectively enhanced by the presence of B. burgdorferi in Ixodes scapularis, first indicating that spirochaetes might use Salp15 during transmission. Salp15 was then shown to adhere to the spirochaete, both in vitro and in vivo, and specifically interacted with $B$. burgdorferi outer surface protein C. The binding of Salp15 protected B. burgdorferi from antibody-mediated killing in vitro and provided spirochaetes with a marked advantage when they were inoculated into naive mice or animals previously infected with B. burgdorferi. Moreover, RNA interferencemediated repression of Salp15 in I. scapularis drastically reduced the capacity of tick-borne spirochaetes to infect mice. These results showed the capacity of a pathogen to use a secreted arthropod protein to help it colonize the mammalian host. Based on the results descrived above, tick derived molecules like TROSPA and Salp15 appear to be possible candidate for a pathogen blocking vaccine.

\section{CONCLUSION}

Prior to recent advances in molecular biological technology, the major limitation in this research area was absence of a sustainable practical approach to produce recombinant antigens in vitro for further analysis. Now, this limitation has already been overcome and therefore future studies should focus on identification and characterization of tick proteins responsible for modulation of host immune response and homeostasis as well as pathogen transmission. Once recombinant molecules of interest are obtained, studies to clearly discern the molecular basis of these proteins will be carried out. The outcome of theses studies will provide fundamental information to explore and develop effective tick vaccine applicable to field use.

\section{REFERENCES}

1 Ackerman S., Clare F.B., McGill T.W. \& Sonenshine D.E. 1981. Passage of host serum components, including antibody, across the digestive tract of Dermacentor variabilis (Say). Journal of Parasitology. 67: 737-740.

2 Almazan C., Blas-Machado U., Kocan K.M., Yoshioka J.H., Blouin E.F., Mangold A.J. \& de la Fuente J. 2005. Characterization of three Ixodes scapularis cDNAs protective against tick infestations. Vaccine. 23: 4403-4416.

3 Almazán C., Kocan K.M., Blouin E.F. \& de la Fuente J. 2005. Vaccination with recombinant tick antigens for the control of Ixodes scapularis adult infestations. Vaccine. 23: 5294-5298.

4 Andreotti R., Gomes A., Malavazi-Piza K.C., Sasaki S.D., Sampaio C.A. \& Tanaka A.S. 2002. BmTI antigens induce a bovine protective immune response against Boophilus microplus tick. International Immunopharmacology. 2: 557-563.

5 Bior A.D., Essenberg R.C. \& Sauer J.R. 2002. Comparison of differentially expressed genes in the salivary glands of male ticks, Amblyomma americanum and Dermacentor andersoni. Insect Biochemistry and Molecular Biology. 32: 645-655. 
6 Bishop R., Lambson B., Wells C., Pandit P., Osaso J., Nkonge C., Morzaria S., Musoke A. \& Nene V. 2002. A cement protein of the tick Rhipicephalus appendiculatus, located in the secretory e cell granules of the type III salivary gland acini, induces strong antibody responses in cattle. International Journal of Parasitology. 32: 833-842.

7 Bode W. \& Huber R. 1992. Natural protein proteinase inhibitors and their interaction with proteinases. European Journal of Biochemistry. 204: 433-451.

8 Brossard M. \& Wikel S.K. 2004. Tick immunobiology. Parasitology. 129. Suppl: S161-176.

9 Crampton A.L., Miller C., Baxter G.D. \& Barker S.C. 1998. Expressed sequenced tags and new genes from the cattle tick, Boophilus microplus. Experimental and Applied Acarology. 22: 177-186.

10 Davie E.W., Fujikawa K. \& Kisiel W. 1991. The coagulation cascade: initiation, maintenance, and regulation. Biochemistry 30. pp. 10363-10370.

11 De la Fuente J. \& Kocan K.M. 2006. Strategies for development of vaccines for control of ixodid tick species. Parasite Immunology. 28: 275-283.

12 De La Fuente J., Rodriguez M. \& Garcia-Garcia J.C. 2000. Immunological control of ticks through vaccination with Boophilus microplus gut antigens. Annals of the New York Academy of Sciences. 916: 617-621.

13 De la Fuente J., Rodriguez M., Redondo M., Montero C., Garcia-Garcia J.C., Mendez L., Serrano E., Valdes M., Enriquez A., Canales M., Ramos E., Boue O., Machado H., Lleonart R., de Armas C.A., Rey S., Rodriguez J.L., Artiles M. \& Garcia L. 1998. Field studies and cost-effectiveness analysis of vaccination with Gavac (TM) against the cattle tick Boophilus microplus. Vaccine. 16: 366-373.

14 De Vos S., Zeinstra L., Taoufik O., Willadsen P. \& Jongejan F. 2001. Evidence for the utility of the Bm86 antigen from Boophilus microplus in vaccination against other tick species. Experimental and Applied Acarology. 25: 245-261.

15 Ferreira C.A., Da Silva Vaz I., da Silva S.S., Haag K.L., Valenzuela J.G. \& Masuda A. 2002. Cloning and partial characterization of a Boophilus microplus (Acari: Ixodidae) calreticulin. Experimental Parasitology. 101:25-34.

16 Fivaz B.H., Nurton J.P. \& Pentry T.N. 1991. Resistance of restrained Bos taurus dairy bull calves to the bont tick Amblyomma hebraeum (Acari: Ixodidae). Veterinary Parasitology. 38: 299-315.

17 Fragoso H., Rad P.H., Ortiz M., Rodriguez M., Redondo M., Herrera L. \& De la Fuente J. 1998. Protection against Boophilus annulatus infestations in cattle vaccinated with the B. microplus Bm86-containing vaccine Gavac. Vaccine. 16: 1990-1992.

18 Francischetti I.M., My Pham V., Mans B.J.,Andersen J.F., Mather T.N., Lane R.S. \& Ribeiro J.M. 2005. The transcriptome of the salivary glands of the female western black-legged tick Ixodes pacificus (Acari: Ixodidae). Insect Biochemistry and Molecular Biology. 35: 1142-1161.

19 Francischetti I.M., Valenzuela J.G., Andersen J.F., Mather T.N. \& Ribeiro J.M. 2002. Ixolaris, a novel recombinant tissue factor pathway inhibitor (TFPI) from the salivary gland of the tick, Ixodes scapularis: identification of factor X and factor $\mathrm{Xa}$ as scaffolds for the inhibition of factor VIIa/tissue factor complex. Blood. 99: 3602-3612.

20 Fujisaki K., Kamio T. \& Kitaoka S. 1984. Passage of host serum components, including antibodies specific for Theileria sergenti, across the digestive tract of argasid and ixodid ticks. Annalas of Tropical Medicine and Parasitology. 78: 449-450.

21 Garcia-Garcia J.C., González I.L., González D.M., Valdes M., Mendez L., Lamberti J., D’Agostino B., Citroni D., Fragoso H., Ortiz M., Rodriguez M., De la Fuente J. 1999. Sequence variation in the Boophilus microplus Bm86 locus and implications for immunoprotection in cattle vaccinated with this antigen. Experimental and Applied Acaroogy. 23: 883-895.

22 García-García J.C., Montero C., Redondo M., Vargas M., Canales M., Boue O., Rodriguez M., Joglar M., Machado H., Gonzalez I.L., Valdes M., Mendez L. \& De la Fuente J. 2000. Control of ticks resistant to immunization with Bm86 in cattle vaccinated with the recombinant antigen Bm95 isolated from the cattle tick, Boophilus microplus. Vaccine. 18: $2275-2287$.

23 Gaspar A.R., Crause J.C. \& Neitz A.W. 1995. Identification of anticoagulant activities in the salivary glands of the soft tick, Ornithodoros savignyi. Experimental and Applied Acarology. 19: 117-127.

24 Gomes-Solecki M.J., Brisson D.R. \& Dattwyler R.J. 2006. Oral vaccine that breaks the transmission cycle of the Lyme disease spirochete can be delivered via bait. Vaccine. 24: 4440-4449.

25 Hill C.A. \& Gutierrez J.A. 2000. Analysis of the expressed genome of the lone star tick, Amblyomma americanum (Acari: Ixodidae) using an expressed sequence tag approach. Microbial \& comparative genomics. 5: 89-101.

26 Imamurs S., Namangala B., Tajima T., Tembo M.E., Yasuda J., Ohashi K. \& Onuma M. 2006. Two serine protease inhibitors (serpins) that induced a bovine protective immune response against Rhipicephalus appendiculatus ticks. Vaccine. 24: 2230-2237. 
27 Imamura S., Vaz Junior I da S., Sugino M., Ohashi K. \& Onuma M. 2005. A serine protease inhibitor (serpin) from Haemaphysalis longicornis as anti-tick vaccine. Vaccine. 23: 1301-1311.

28 Imler J.L. \& Hoffmann J.A. 2000. Signaling mechanisms in the antimicrobial host defense of Drosophila. Current Opinion in Microbiology. 3: 16-22.

29 Iwanaga S., Kawabata S. \& Muta T. 1998. New types of clotting factors and defense molecules found in horseshoe crab hemolymph: their structures and functions. Journal of Biochemistry (Tokyo). 123: 1-15.

30 Iwanaga S., Okada M., Isawa H., Morita A., Yuda M. \& Chinzei Y. 2003. Identification and characterization of novel salivary thrombin inhibitors from the ixodidae tick, Haemaphysalis longicornis. European Journal of Biochemistry. 270: 19261934.

31 Jaworski D.C., Simmen F.A., Lamoreaux W., Coons L.B., Muller M.T. \& Needman G.R. 1995. A secreted calreticulin protein in ixodid tick (Amblyomma americanum) saliva. Journal of Insect Physiology. 41: 369-375

32 Kanost M.R. 1999. Serine proteinase inhibitors in arthropod immunity. Developmental and Comparative Immunology. 23 : 291-301.

33 Kanost M.R. \& Jiang H. 1996. Protease inhibitors in invertebrate immunity. In new directions in invertebrate immunology. eds Soderhall K., Iwanaga S. \& Vanta G. SOS Publications. 155-173.

34 Kay B.H. \& Kemp D.H. 1994. Vaccines against arthropods. American Journal of Tropical Medicine Hygiene. 50: 87-96.

35 Kazimirova M., Jancinova V., Petrikova M., Takac P., Labuda M.\& Nosal'R. 2002. An inhibitor of thrombin-stimulated blood platelet aggregation from the salivary glands of the hard tick Amblyomma variegatum (Acari: Ixodidae). Experimental and Applied Acarology. 28: 97-105.

36 Kemp D.H., Stone B.F. \& Binnington K.C. 1982. Tick attachment and feeding: role of the mouthparts, feeding apparatus, salivary gland secretions and host response. In physiology of ticks. eds Obenchain F.D. \& Galun R. Oxford: Pergamon Press. 119-168.

37 Labuda M., Trimnell A.R., Lickova M., Kazimirova M., Davies G.M., Lissina O., Hails R.S. \& Nuttall P.A. 2006. An antivector vaccine protects against a lethal vector-borne pathogen. PLoS Pathogens. 2: e27.

38 Laskowski M. \& Qasim M.A. 2000. What can the structures of enzyme-inhibitor complexes tell us about the structures of enzyme substrate complexes? Biochimica et Biophysica Acta. 1477: 324-337.

39 Laskowski M. Jr., \& Kato I. 1980. Protein inhibitors of proteinases. Annual Review of Biochemistry. 49: 593-626.

40 Leboulle G., Crippa M., Decrem Y., Mejri N., Brossard M., Bollen A. \& Godfroid E. 2002. Characterization of a novel salivary immunosuppressive protein from Ixodes ricinus ticks. Journal of Biological Chemistry. 277: 10083-10089.

41 Mans B.J. \& Neitz A.W. 2004. Adaptation of ticks to a blood-feeding environment: evolution from a functional perspective. Insect Biochemistry and Molecular Biology. 34: 1-17.

42 McKenna R.V., Riding G.A., Jarmey J.M., Pearson R.D. \& Willadsen P. 1998. Vaccination of cattle against the Boophilus microplus using a mucin-like membrane glycoprotein. Parasite Immunology. 20: 325-336.

43 Mukhebi A.W. 1992. Economic impact of theileriosis and its control in Africa. In The epidemiology of theileriosis in Africa. Eds. Norval R.A.I., Perry B.D. \& Young A.S. Academic Press. 379-403.

44 Mulenga A., Sugimoto C. \& Onuma M. 2000. Issues in tick vaccine development: identification and characterization of potential candidate vaccine antigens. Microbes and Infection. 2: 1353-1361.

45 Mulenga A., Sugimoto C., Sako Y., Ohashi K., Musoke A., Shubash M. \& Onuma M. 1999. Molecular characterization of a Haemaphysalis longicornis tick salivary gland-associated 29-kilodalton protein and its effect as a vaccine against tick infestation in rabbits. Infection and Immunity. 67: 1652-1658.

46 Mulenga A., Tsuda A., Onuma M. \& Sugimoto C. 2003. Four serine proteinase inhibitors (serpin) from the brown ear tick, Rhiphicephalus appendiculatus; cDNA cloning and preliminary characterization. Insect Biochemistry and Molecular Biology. 33: 267-276.

47 Nakajima C., Imamura S., Konnai S., Yamada S., Nishikado H., Ohashi K. \& Onuma M. 2006. A novel gene encoding a thrombin inhibitory protein in a cDNA library from Haemaphysalis longicornis salivary gland. Journal of Veterinary Medical Science. 68: 447-452.

48 Nakajima C., Vaz Junior Ida S., Imamura S., Konnai S., Ohashi K. \& Onuma M. 2005. Random sequencing of cDNA library derived from partially-fed adult female Haemaphysalis longicornis salivary gland. Journal of Veterinary Medical Science. 67: 1127-1131.

49 Nene V., Lee D., Kang'a S., Skilton R., Shah T., de Villiers E., Mwaura S., Taylor D., Quackenbush J. \& Bishop R. 2004. Genes transcribed in the salivary glands of female Rhipicephalus appendiculatus ticks infected with Theileria parva. Insect Biochemistry and Molecular Biology. 34: 1117-1128. 
50 Nene V., Lee D., Quackenbush J., Skilton R., Mwaura S., Gardner M.J. \& Bishop R. 2002. AvGI, an index of genes transcribed in the salivary glands of the ixodid tick Amblyomma variegatum. International Journal of Parasitology. 32: 1447-1456.

51 Nienaber J., Gaspar A.R. \& Neitz A.W. 1999. Savignin, a potent thrombin inhibitor isolated from the salivary glands of the tick Ornithodoros savignyi (Acari: Argasidae). Experimantal Parasitology. 93: 82-91.

52 Nolan J. 1990. Acaricide resistance in single and multi-host ticks and strategies for control. Parassitologia; 32: $145-153$.

53 Norval R.A., Lawrence J.A., Young A.S., Perry B.D., Dolan T.T. \& Scott J. 1991. Theileria parva: influence and host relationships on the epidemiology of theileriosis in southern Africa. Parasitology. 102: 347-356.

54 Norval R.A., Yumker C.E. \& Butler J.F. 1987. Field sampling of unfed adults of Amblyomma hebraeum Koch. Experimental and Applied Acarology. 3: 213-217.

55 Nuttall P.A., Trimnell A.R., Kazimirova M. \& Labuda M. 2006. Exposed and concealed antigens as vaccine targets for controlling ticks and tick-borne diseases. Parasite Immunology. 28: 155-63.

56 Obechan F.D. \& Galun R. 1982. Physiology of Ticks. Oxford. Pergamon Press.

57 Opdebeeck J.P. 1994. Vaccines against blood-sucking arthropods. Veterinary Parasitology. 54: $205-222$.

58 Paesen G.C., Adams P.L., Nuttall P.A. \& Stuart D.L. 2000. Tick histamine-binding proteins: lipocalins with a second binding cavity. Biochimica et biophysica acta. 1482: 92-101.

59 Pal U., Li X., Wang T., Montgomery R.R., Ramamoorthi N., Desilva A.M., Bao F., Yang X., Pypaert M., Pradhan D., Kantor F.S., Telford S., Anderson J.F. \& Fikrig E. 2004. TROSPA, an Ixodes scapularis receptor for Borrelia burgdorferi. Cell. 119: 457-468.

60 Pegram R.G. Lemche J., Chizyuka H.G., Sutherst R.W., Floyd R.B., Kerr J.D. \& McCosker P.J. 1989. Effect of the tick control on liveweight gain of cattle in central Zambia. Medical and Veterinary Entomology. 3: 313-320.

61 Pham T.N., Hayashi K., Takano R., Itoh M., Eguchi M., Shibata H. Tanaka T. \& Hara S. 1996. A new family of serine proteinase inhibitors (Bombyx family) as established from the unique topological relation between the positions of disulphide bridges and reactive site. Journal of Biochemistry (Tokyo). 119: 428-434.

62 Polanowski A. \& Wilusz T. 1996. Serine proteinase inhibitors from insect hemolymph. Acta Biochimica Polonica. 43: 445-453.

63 Ramamoorthi N., Narasimhan S., Pal U., Bao F., Yang X.F., Fish D., Anguita J., Norgard M.V., Kantor F.S., Anderson J.F., Koski R.A. \& Fikrig E. 2005. The Lyme disease agent exploits a tick protein to infect the mammalian host.Nature. 436: 573-577.

64 Rand K.N., Moore T., Sriskantha A., Spring K., Tellam R., Willadsen P. \& Coban G.S. 1989. Cloning and expression of a protective antigen from the cattle tick Boophilus microplus. Proceedings of the National Academy of Sciences of the United States of America. 86: 9657-9651.

65 Ribeiro J.M. 1987. Role of saliva in blood-feeding by arthropods. Annual Review of Entomology. 32:463-78.

66 Riding G.A., Jarmey J., McKenna R.V., Pearson R., Cobon G.S. \& Willadsen P.A. 1994. Protective “concealed” antigen from Boophilus microplus. Purification, localization, and possible function. Journal of Immunology. 153: 5158-5166.

67 Rubin H. 1996. Serine protease inhibitors (SERPINS); where mechanism meets medicine. Nature Medicine. 2: 632-633.

68 Simonet G., Claeys I. \& Broeck J.V. 2002. Structural and functional properties of a novel serine protease inhibiting peptide family in arthropods. Comparative Biochemistry and Physiology. Part B, Biochemistry and Molecular Biology. 132: 247-255.

69 Sonenshine D.E. 1993. Biology of Ticks. Oxford University Press. Oxford.

70 Sugino M., Imamura S., Mulenga A., Ohashi K. \& Onuma M. 2003. A serine proteinase inhibitor (serpin) from ixodid tick Haemaphysalis longicornis; cloning and preliminary assessment of its suitability as a candidate for a tick vaccine. Vaccine 21: 2844-2851.

71 Sutherst R.W., Jones R.J. \& Schnitzerling H.J. 1982. Tropical legumes of the genus Stylosanthes immobilize and kill cattle tick. Nature 295: 320-322.

72 Tanaka A.S., Andreotti R., Gomes A., Torquato R.J., Sampaio M.U. \& Sampaio C.A. 1999. A double headed serine proteinase inhibitor - human plasma kallikrein and elastase inhibitor - from Boophilus microplus larvae. Immunopharmacology. 45: 171-177.

73 Tellam R.L., Kemp D., Riding G., Briscoe S., Smith D., Sharp P., Irving D. \& Willadsen P. 2002. Reduced oviposition of Boophilus microplus feeding on sheep vaccinated with vitellin. Veterinary Parasitology. 103:141-156. 
74 Tellam R.L., Smith D., Kemp D.H. \& Willadsen P. 1992. Vaccination against ticks. In Animal parasite control utilizing biotechnology. Wong W.K. edt. Boca Raton. CRC Press. 303-331.

75 Trager W. 1939. Acquired immunity to ticks. Journal of Entomology. 25: 57-58.

76 Trimnell A.R., Davies G.M., Lissina O., Hails R.S. \& Nuttall P.A. 2005. A cross-reactive tick cement antigen is a candidate broad-spectrum tick vaccine. Vaccine. 23: 4329-41.

77 Tsuda A., Mulenga A., Sugimoto C., Nakajima M., Ohashi K. \& Onuma M. 2001. cDNA cloning, characterization and vaccine effect analysis of Haemaphysalis longicornis tick saliva proteins. Vaccine. 19: 4287-4296.

78 Valenzuela J.G. 2002. Exploring the messages of the salivary glands of Ixodes ricinus. The American Journal of Tropical Medicine and Hygiene. 66: 223-224.

79 Valenzuela J.G., Francischetti I.M., Pham V.M., Garfield M.K., Mather T.N. \& Ribeiro J.M. 2002. Exploring the sialome of the tick Ixodes scapularis. The Journal of Experimental Biology. 205: 2843-2864.

80 Valle M.R., Mendez L., Valdez M., Redondo M., Espinosa C.M., Vargas M., Cruz R.L., Barrios H.P., Seoane G., Ramirez E.S., Boue O., Vigil J.L., Machado H., Nordelo C.B. \& Pineiro M.J. 2004. Integrated control of Boophilus microplus ticks in Cuba based on vaccination with the anti-tick vaccine Gavac. Experimental and Applied Acarology. 34: $375-382$.

81 Van de Locht A., Stubbs M.T., Bode W., Friedrich T., Bollschweiler C., Hoffken W. \& Huber R. 1996. The ornithodorinthrombin crystal structure, a key to the TAP enigma? The EMBO Journal. 15: 6011-6017.

82 Van Gent D., Sharp P., Morgan K. \& Kalsheker N. 2003. Serpins: structure, function and molecular evolution. The International Journal of Biochemistry and Cell Biology. 35: 1536-1547.

83 Vaz Junior I. da S., Martinez R.H., Oliveira A., Heck A., Logullo C., Gonzales J.C., Dewes H. \& Masuda A. 1996. Functional bovine immunoglobulins in Boophilus microplus hemolymph. Veterinary Parasitology. 62: 155-160.

84 Wang H. \& Nuttall P.A. 1995. Immunogloblin G binding proteins in male Rhipicephalus appendiculatus ticks. Parasite Immunology. 17: 517-524.

85 Waxman L., Smith D.E., Arcuri K.E. \& Vlasuk G.P. 1990. Tick anticoagulant peptide (TAP) is a novel inhibitor of blood coagulation factor Xa. Science. 248: 593-596.

86 Weiss B.L. \& Kaufman W.R. 2004. Two feeding-induced proteins from the male gonad trigger engorgement of the female tick Amblyomma hebraeum. Proceedings of the National Academy of Sciences of the United States of America. 101: 58745879.

87 Wikel S.K. 1982. Immune responses to arthropods and their products. Annual Review of Entomology. 27: 21-48.

88 Wikel S.K. 1988. Immunological control of hematophagous arthropod vectors: utilization of novel antigens. Veterinary Parasitology. 29: 235-264.

89 Wikel S.K. 1996. Host immunity to ticks. Annual Review of Entomology. 41: 1-22.

90 Willadsen P. 1980. Immunity to ticks. Advances in Parasitology. 18: 293-313.

91 Willadsen P., Bird P., Cobon G.S. \& Hungerford J. 1995. Commercialisation of a recombinant vaccine against Boophilus microplus. Parasitology. 110 Suppl: 43-50.

92 Willadsen P. \& Jongejan F. 1999. Immunology of the tick-host interaction and the control of ticks and tick-borne diseases. Parasitology. Today. 15: 258-62.

93 Willadsen P. \& Kemp D.H. 1988. Vaccination with 'concealed' antigens for tick control. Prasitology Today. 4: $196-198$.

94 Willadsen P., Riding G.A., McKenna R.V., Kemp D.H., Tellam R.L., Nielsen J.N., Lahnstein J., Cobon G.S. \& Gough J.M. 1989. Immunologic control of a parasitic arthropod. Identification of a protective antigen from Boophilus microplus. Journal of Immunology. 143: 1346-1351.

95 Willadsen P., Smith D., Cobon G. \& McKenna R.V. 1996. Comparative vaccination of cattle against Boophilus microplus with recombinant antigen Bm86 alone or in combination with recombinant Bm91. Parasite Immunology. 18: 241-246

96 You M.J. 2005. Immunization of mice with recombinant P27/30 protein confers protection against hard tick Haemaphysalis longicornis (Acari: Ixodidae) infestation. Journal of Veterinary Science. 6: 47-51.

97 Zhou J., Gong H., Zhou Y., Xuan X. \& Fujisaki K. 2006. Identification of a glycine-rich protein from the tick Rhipicephalus haemaphysaloides and evaluation of its vaccine potential against tick feeding. Parasitology Research. Jun 27. Epub ahead of print.

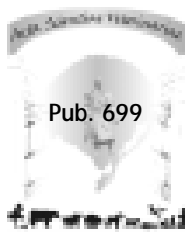

